\title{
ANNOUNCEMENT \\ 24th FORUM ON THE GEOLOGY OF INDUSTRIAL MINERALS
}

\author{
Greenville, South Carolina
}

May 2-5, 1988

Technical Sessions:

Field Trips:

Further Information:
Heavy Minerals, Dimension Stone, Kaolin, Phosphate, Cement, Talc, Lithium-Spodumene Pegmatites, Vermiculite, Ochre, Fullers Earth, Brick Industry

Lithium-spodumene pegmatite mine and processing plant, dimension stone quarry, mica mine, brick plant, undeveloped talc deposit, vermiculite mine and processing plant, granite crushed stone operation

Alan-Jon W. Zupan

South Carolina Geological Survey

Harrison Forest Road

Columbia, South Carolina 29210

803-737-9440 